\title{
Dust Suppression with Glycerin from Biodiesel Production: A Review
}

\author{
Wei Yan $^{1}$, S. Kent Hoekman ${ }^{2 *}$ \\ ${ }^{1}$ Gas Technology Institute, Birmingham, USA; ${ }^{2}$ Division of Atmospheric Science, Desert Research Institute, Reno, USA. \\ Email: *Kent.Hoekman@dri.edu
}

Received December $3^{\text {rd }}$, 2011; revised January $4^{\text {th }}$, 2012; accepted February $5^{\text {th }}, 2012$

\begin{abstract}
An increasing number of countries and areas in the world suffer from either natural or anthropogenic dust, which results in a serious hazard with respect to the environment and to personal health and safety. This paper reviews and summarizes open literature involving the use of glycerin in dust control applications. Glycerin, a by-product from biodiesel manufacturing, has been evaluated for dust suppressant performance when applied alone as aqueous solutions, or in combinations with surfactants, polymers, or other chemicals. There are reports indicating that glycerin is effective in some dust suppression applications, although details about its use and performance metrics are generally lacking. Recent growth of the biodiesel industry has significantly increased the supply of crude glycerin, making it an economically attractive material for use in dust suppression. This paper also highlights several environmental accidents caused by irresponsible discharges of crude glycerin, and points out the need to understand environmental consequences of glycerin and its impurities when used in dust suppression applications.
\end{abstract}

Keywords: Dust Suppression; Glycerin; Biodiesel By-Product; Economic/Environmental Impact

\section{Introduction}

Sources of dust, including tephra, occur globally, but the major source regions lie in and around the extremely arid to semi-arid dryland of the world. The largest of these stretches over 10,000 km, from the western Sahara in North Africa, through the Middle East, to central and eastern Asia [1,2].

Sources of erodible natural dust are found in wadis, salt pans, and alluvial deposits, as well as in ephemeral, saline, and dry lakes through North Africa, the Middle East, the northwestern Indian subcontinent, central Asia, and northwestern China. The extent to which particles are taken up from the ground surface depends on several factors: the critical wind speed necessary to dislodge particles (known as the threshold velocity); the instability of the atmosphere; particle size; the degree of particle exposure; vegetation cover; and the mineralogical composition of loose dust on the ground surface [1,2].

Human activities also generate substantial amounts of dust. Anthropogenically disturbed land can become major dust sources, especially in the drought-stricken agricultural regions of Africa, Australia, China, and the U.S. Midwest. Estimates of the magnitude of anthropogenic contributions to global dust load range from less than 10 $\mathrm{wt} \%$ to $50 \mathrm{wt} \%$, a range of variation that reflects model-

*Corresponding author. ing uncertainties and a dearth of measured observational data. More recently, however, direct measurements with satellite-borne spectroradiometers, combined with surface land-use data, show that in regions where 5\% - 25\% of the land surface is disturbed, more than half the territory is potentially an anthropogenic dust source [1-3].

Mineral dust is composed of variable amounts of quartz, feldspars, micas, various clay minerals, carbonates, oxides and evaporative minerals. Minerals in dust occur as individual grains, aggregates or surface coatings-from less than $1 \mu \mathrm{m}$ to $\sim 30 \mu \mathrm{m}$ in diameter. Dust entrainment by saltation and suspension processes takes place mostly when winds are strong and gusty. Freshly entrained dust may initially have a mineral composition similar to that of the surface soil. Particle segregation and deposition of coarse materials takes place over short distances, depending on the mineralogical composition and the physical properties of the dust. Fine and low-density particles remain in suspension and are lofted into the upper troposphere, where they can circle the globe. Airborne dust also carries micro fauna, including diatoms, bacteria and viruses; some of the latter remain alive despite being transported for distances of several thousand kilometers [4]. African dust outbreaks are partly responsible for exceeding the maximum particle concentrations permitted by air quality guidelines in southern Europe. 
Fugitive dust from dirt surfaces, and the handling of bulk products with attendant particulate materials, can generate significant health, environmental and safety problems. In mining facilities, industrial sites and construction sites, the operations may be significantly restricted by dust cloud formation. Also health, environmental and safety problems may arise when any kind of dust is inhaled [2-4].

\section{Dust Control Using Dust Suppressant}

Fugitive dust is a major contributor to suspended ambient particles and comprises a large portion of PM 10 and PM 2.5 , which are particulate matter with aerodynamic diameter less than $10 \mu \mathrm{m}$ and $2.5 \mu \mathrm{m}$, respectively. In the United States, this is especially significant in the western arid and semi-arid regions. Fugitive dust is a common problem on unpaved roads, in underground mines such as coal mines and other types of underground mines, on mineral storage piles and tailings impoundments, and in various other areas where coal particles, rock dust, clay, slate, soil, and other finely divided particles are present on various types of surfaces. Fugitive dust is also a problem in transit when pulverized minerals and/or coals are shipped in rail cars or trucks, resulting in material losses by wind erosion during transit.

Dust suppression is defined as the prevention or reduction of the amount of fine particulates airborne or suspended in the air. There are mechanical and chemical methods for dust suppression. Mechanical methods include dust collection equipment (e.g. filters and cyclones), to capture entrained dust, induce dust to settle, and ventilate the area where dust is formed. Chemical methods include short and long term residual suppressants. One of common short-term methods for mitigating dust is to apply a water spray, which is done from a water truck equipped with either a pressurized spray system or a gravity fed distribution box. Such water trucks are commonly used, for example, on mine haulage roads, quarry access and haulage roads, and other types of dusty areas supporting traffic. One disadvantage of water spray is the large quantity of water needed to effectively control the dust. Another problem is that dust is controlled for only a short period of time depending on weather conditions, and the application of the spray has to be repeated frequently [5-8].

Long term dust suppression can be achieved by forming a binder or polymer film over the dusting material. The film remains after evaporation of the solvent (e.g. water). Water is also used in long-term dust suppression to ensure an even spreading. To enhance the effectiveness of water spray, hygroscopic salts are often incorporated in water, enhancing moisture retention on the dusty surface. Halide brines, comprising one or more dissolved or suspended salts in water are used extensively for inhibiting dust from a variety of surfaces, and for controlling dust during the handling and transportation of dustproducing bulk materials. A disadvantage of this method is the high salt usage rates. Moreover, aqueous solutions of these halides are known to corrode metals and cause scaling or surface damage to concrete [9].

Oil-type sprays (e.g. polyvinyl acetate and styrene butadiene resins) have also been applied either directly or as asphalt or oil emulsions [10-12]. For example, Gillies et al. [12] performed a 14-month study to assess the long-term efficiencies of four dust suppressants (biocatalyst stabilizer, polymer emulsion, petroleum emulsion with polymer, and nonhazardous crude-oil-containing materials) to reduce the emission of PM10 from public unpaved roads. The results showed that one week after application, suppressant efficiencies ranged between 33\% and $100 \%$ for the four types applied. After $8-12$ months of exposure to weathering and 4900 - 6400 vehicle passes, the suppressant efficiencies ranged from zero to $95 \%$. Suppressant materials that created surface conditions resistant to brittle failure were less prone to deterioration and more likely to increase long-term reduction efficiency for PM10 emissions on these unpaved roads.

In some cases, a disadvantage of oil-type dust suppression is the tendency of these materials to adhere to vehicle tires and other objects which come into contact with them. Also, the required dosages can be quite high. In some instances, this type of application also causes environmental and health concerns [10].

\section{Glycerin Used for Dust Suppression}

In the arid regions of Western and Southwestern U.S., dust poses a serious and costly air quality problem. Several counties in Nevada, Utah, California, Colorado, Arizona, New Mexico, and Texas have been struggling to attain the National Ambient Air Quality Standard (NAAQS) for PM 10. This is due largely to the amount of dust that is available for emission into the atmosphere. Currently, there are few widely accepted, inexpensive, environmentally compatible dust suppressants available on the market. Crude glycerin, or a product containing a large proportion of glycerin, might serve as a suitable dust suppressant that meets these criteria in certain applications.

Crude glycerin is formed as a byproduct in the manufacturing of biodiesel. Conventional production of biodiesel involves chemical reaction of triacylglycerides (from vegetable oils and animal fats) with methanol (or ethanol). This process, called transesterification, is catalyzed by either strong acid or base. Most biodiesel produced today utilizes base catalyzed reaction, because of its low cost, rapid reaction rate, and high conversion with 
minimal side reactions [13]. For example, $100 \mathrm{~kg}$ of vegetable oil may be reacted with an appropriate amount of methanol (approx. $10 \mathrm{~kg}$ ) to yield about $100 \mathrm{~kg}$ of fatty acid methyl ester (FAME; also known as biodiesel) and $10 \mathrm{~kg}$ of glycerin. Once the reaction is complete, excessive alcohol is recovered by distillation or other separation processes, and crude glycerin is drawn off the bottom of a settling vessel. The crude glycerin is usually basic, due to the presence of excessive sodium or potassium hydroxide catalyst. It is neutralized with acids such as hydrochloride acid, thus forming inorganic salts in crude glycerin [5-7]. Currently, the major feedstocks for biodiesel are soy oil (in the U.S.), rapeseed oil (in Europe) and palm oil (in Asia), although there is considerable interest in utilizing algal lipids and other materials as feedstocks [13].

Crude glycerin generated from biodiesel production is impure and of little economic value. In general, glycerin itself makes up only $65 \%$ to $85 \%(\mathrm{w} / \mathrm{w})$ of the crude product stream $[14,15]$. The wide range of purity values can be attributed to different glycerin purification methods and different feedstocks used by biodiesel producers. Thompson and He [16] have characterized glycerin produced from various biodiesel feedstocks and found that mustard seed generated a lower purity level of glycerin (62\%), while soy oil produced $67.8 \%$ pure glycerin, and waste vegetable oil produced $76.6 \%$ pure glycerin.

Kinast [17] mentioned in a NREL report that other uses of crude glycerin have been considered, including for dust suppression on highways and other dirt roads. It has been reported that concentrated crude glycerin is highly effective for dust control, and in some cases, it outperforms other dust control agents. For example, concentrated crude glycerin was applied to a dirt road located in a sand and gravel processing facility $[5,6]$. This material was about $80 \mathrm{wt} \%$ glycerin, 10 - $11 \mathrm{wt} \%$ water, $7 \mathrm{wt} \%$ sodium chloride, and 1 - $2 \mathrm{wt} \%$ fatty acids and methyl esters. An initial application used a mixture of 70 wt\% crude glycerin in water. Four weeks later, a "maintenance dose" was applied, consisting of a mixture of 20 wt\% crude glycerin in water. The level of dust control achieved was considered acceptable and the customer placed a large order for crude glycerin for use as a dust control agent on this dirt road [5,6]. Tran and Bhattacharja $[5,6]$ also described use of diluted crude glycerin for dust suppression. A mixture of $40 \mathrm{wt} \%$ crude glycerin in water was applied to a dusty road at a dosage of one quart per square yard. This treatment was shown to be somewhat effective in suppressing dust from vehicle traffic for up to four weeks, before a maintenance application was needed.

Compared to the current practice of using just water to control road dust, applications with glycerin can retain effectiveness for a much longer period of time- on the order of weeks, rather than hours. Also, aqueous crude glycerin has a highly depressed freezing point, making it suitable for use at sub-freezing temperatures.

A large number of products and processes have been extensively described in the literature, ranging from the utilization of natural and synthetic polymers and also using mixtures and combinations of surfactants and organic solvents [18-22]. For example, Grogan [18] investigated the effectiveness of dust control using polyhydric alcohols (including glycerin) alone or in combination with acrylic compounds and polyhydric esters. Results showed that these mixtures were effective in binding particles to the stationary structure, and thus could limit the generation of PM emissions.

Rath and Verral [11] discussed use of solutions containing polyvinyl alcohols (including glycerin) cross linked with borates or boric acid in dust suppression. These solutions reduce water evaporation and run-off tendency, thereby improving their usefulness as dust suppressants. Rather than those cross linking agents that undergo direct chemical condensation reactions with hydroxyl groups, preferred cross linking agents-for reasons of solution stability and rheology-are those that form complexes via polar covalent interactions, or crosslink via ionic interactions and hydrogen bonding interactions. Examples of such cross linking agents are borates and boric acid. The base polymer formula includes glycerin, surfactants, and other minor components like starch. The results showed excellent performance. During the week following application, two hundred vehicles drove on the treated road, without creation of significant dust.

Ogzewalla [23] described a method and composition for controlling dust and anti-caking of solid granular materials, including fertilizers, aggregates, minerals and ores. This patent described the reaction of glycerin with a polybasic acid (e.g. citric acid) to give a polymeric derivative that is applied to the solid granular materials. The data included in the patent (see Table 1) shows the effectiveness of this glycerin derivative in controlling dust on granular borax, compared to various commercial dust suppressants.

\section{Economic Considerations of Glycerin for Dust Suppression}

Biodiesel production is expected to increase in 2011 and beyond, with implementation of the U.S. EPA's RFS2 requirements for biomass-based diesel fuel. This will result in increasing production of glycerin, likely exceeding the market's ability to absorb it [24]. While there are over 2000 uses for glycerin in the drug, food, beverage, chemicals and synthetic material industries, research efforts are underway aimed at exploring other cost-effective 
Table 1. Dust controlling tests with granulated borax [23]. DUSTROL is a trade name for commercial dust control agents, manufactured and sold by ARR-MAZ Custom Chemicals, Inc.

\begin{tabular}{ccccc}
\hline \multicolumn{5}{c}{ Dust test with gran lated borax } \\
\hline \multirow{2}{*}{ Dedusting agent } & $\begin{array}{c}\text { Specific } \\
\text { gravity }\end{array}$ & $\begin{array}{c}\text { Application } \\
\text { rate }\end{array}$ & Dust Levels & $\begin{array}{c}\text { Reduciont } \\
\text { Dust of }\end{array}$ \\
\cline { 3 - 5 } & per pound & mpp & $\%$ \\
\hline None & NA & 0.0 & 15,850 & 0.0 \\
Mineral oil & 0.914 & 7.6 & 9,150 & 42.3 \\
dustrol 3082 & 0.924 & 7.7 & 2,350 & 85.2 \\
Vegetable oil & 0.890 & 7.3 & 3,900 & 75.4 \\
dustrol 3876 & 1.260 & 10.6 & 1,400 & 91.2 \\
Glycerin citic acid & 1.340 & 11.2 & 1,100 & 93.1 \\
\hline
\end{tabular}

uses, such as for producing bio-based propylene glycol or in livestock diets as a replacement for high-priced corn. Although novel uses of glycerin are expected to help consume the increasing amounts of glycerin, supply and demand factors will dictate the market price for crude glycerin (Figure 1, source: The Jacobsen Publishing Company).

As indicated in Figure 1, US crude glycerin (80\% basis) prices have started as low as 4 cents/lb free on board (FOB) in September 2009. Since then, crude glycerin prices have been increasing steadily and reached the peak at 15 cents/lb free on board (FOB) in late 2010. However, the prices were quite volatile and dropped back into the range of 5 - 7 cents/lb free on board (FOB) in mid 2011.
Hence, crude glycerin may serve as a widely accepted, inexpensive, and effective dust suppression agent. Optionally, concentrated crude glycerin may be diluted with water to further reduce the cost per area of surface being treated. The amount of water dilution may vary with the conditions, and may be determined at the site of use (e.g. dirt roads, coal piles), the nature of the particulate matter, and the weather conditions (e.g. temperature, humidity) at the area.

\section{Environmental Impacts of Application of Crude Glycerin to Water and Land}

According to National Biodiesel Board (NBB), biodiesel is nontoxic, biodegradable and suitable for sensitive environments [25]. However, EPA indicates that construction and operation of biodiesel production facilities can have potential environmental impacts [26]. Like most organic materials, vegetable oils and glycerin deplete the oxygen content of water and wetlands very quickly, which can suffocate fish and other organisms. For birds, a vegetable oil spill is just as deadly as a crude oil spill. Moreover, discharges of crude glycerin can prevent residents from using the rivers, which are major recreational areas for fishing, canoeing, and boating. Several states have reported environmental accidents resulting from irresponsible discharges of crude glycerin (see Figures 2 and 3) [26].

In Alabama, Black Warrior Riverkeeper, a nonprofit organization dedicated to protecting and restoring the Black Warrior River and its tributaries, received a report of a fish kill in September 2006 that stretched 20 miles

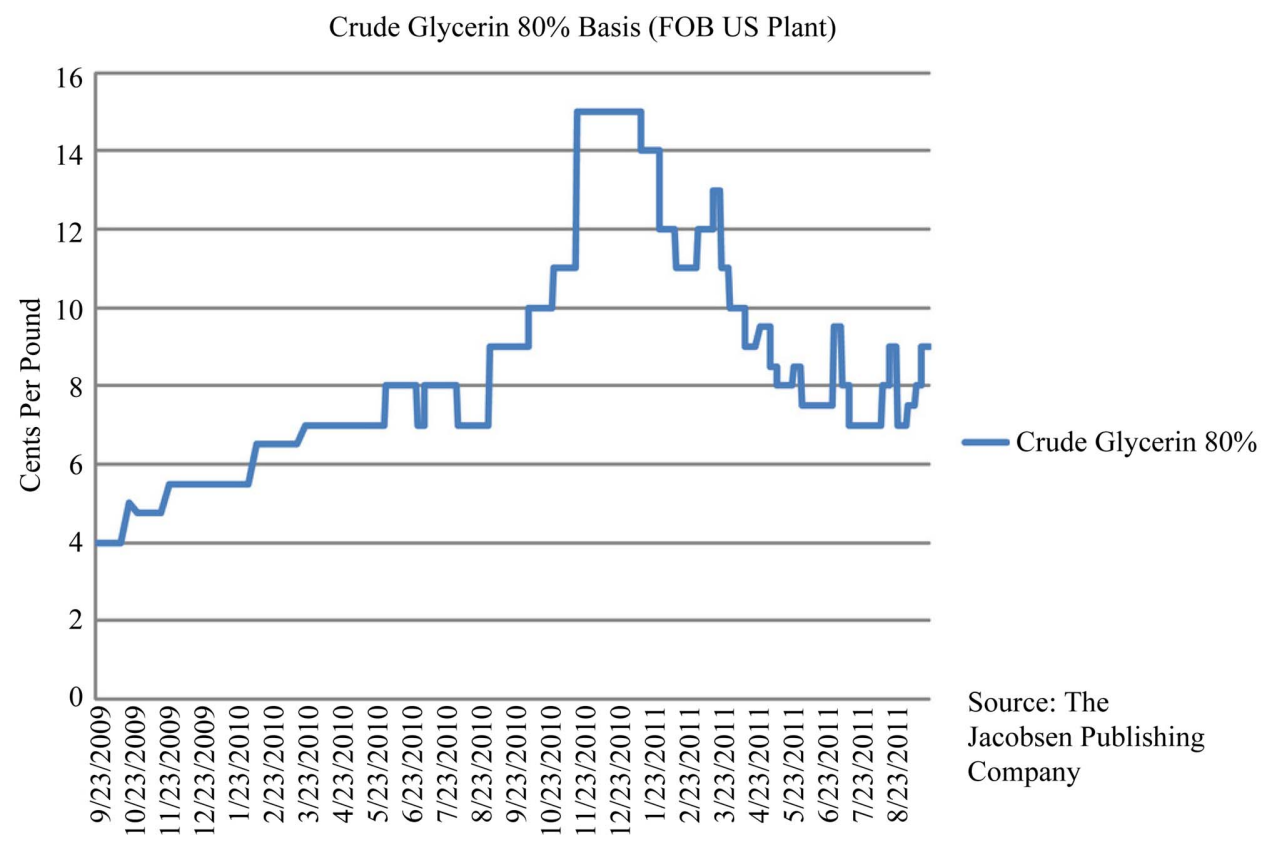

Figure 1. Price trend of crude glycerin from September 2009 to August 2011 (Source: The Jacobsen publishing company). 
downstream from Moundville, Alabama. Riverkeeper found oil around the dead fish, and reported at least 24 occasions where oily material was spotted in the water near a biodiesel plant [27].

In July 2006, a group of golfers on the Meadow Hills Golf Course in Iowa Falls, Iowa, was startled to see dead fish and a milky colored discharge in School Creek, which runs along the course. A subsequent investigation by the Iowa Department of Natural Resources traced the discharge to a biodiesel plant and glycerin refinery. A contractor allegedly disposed of a sludge wastewater mixture from the facilities at a recycling site that seeped into the creek. The biodiesel plant entered into a partial consent order with Iowa and paid a $\$ 100,000$ fine for the pollution, without admitting fault [27].

In October 2007, an anonymous caller reported that a tanker truck dumped "milky white goop" into Belle Fountain Ditch, one of the man-made channels that drain Missouri's Bootheel region. Federal and state responders found decomposing glycerin and methanol generated from a biodiesel plant near Hermondale, Missouri. In January 2008, a grand jury indicated a Missouri businessman who was involved in the discharge, which killed at least 25,000 fish and wiped out the population of fat pocketbook mussel, an endangered species [26,27].

In many states, officials and opponents discussed the propensities for discharges from biodiesel plants to impact dissolved oxygen levels. Pure glycerin has a Biochemical Oxygen Demand (BOD) of nearly 1,000,000 $\mathrm{mg} / \mathrm{L}$ [22]. Recovered wash water used in biodiesel processing can have a BOD of 10,000 - 15,000 mg/L, due largely to the presence of glycerin [26]. With such high BOD levels, discharge of wash water, when degraded by bacteria, can deplete the oxygen content in the water, causing fish and other aquatic life to die. Similar oxygen depletion problems can occur in wet soil. Moreover, crude glycerin does not have any fertilizer value, and will tie up soil nitrogen as it decomposes. For this reason there has been little interest in studying land application. Guidance for the disposal of greasy crude glycerin suggests incorporation and loading rates of about four tons per acre as appropriate to avoid choking of soils. For benign land application of glycerin, loading rates must be low, and runoff control is absolutely essential [26].

The Material Safety Data Sheet (MSDS) categorizes glycerin as an irritant but not necessarily a hazard for humans and animals [28]. Glycerin itself readily degrades in the environment. However, crude glycerin from a biodiesel plant has been described as the wastebasket of the biodiesel process, since much of the oil impurities, methanol and catalyst also go into this phase. These impurities could elevate the environmental risk of crude glycerin. To reduce its environmental impact, it is desir-

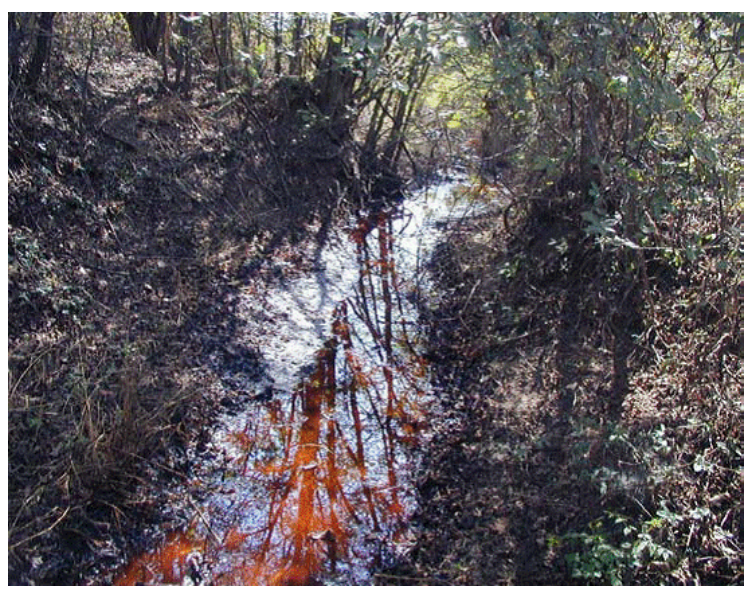

Figure 2. Glycerin polluting creek. (Source: EPA report [26]).

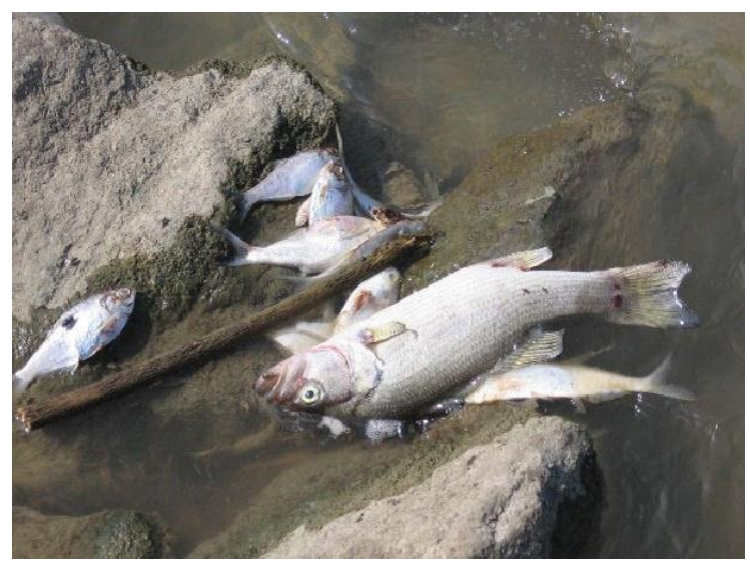

Figure 3. Over 25,000 fish killed in southeastern Missouri, due to illegal dumping of crude glycerin (Source: EPA report [26]).

able to neutralize crude glycerin, depending upon the catalyst used in biodiesel production [27].

Nebraska's Department of Environmental Quality has published a guidance document, which is considered a model in the industry. This document describes a number of factors in considering the potential for a hazardous waste determination, and provides waste management tips for biodiesel plants. High concentrations of methanol and wide variation in the $\mathrm{pH}$ of waste materials tilt the determination toward hazardous materials. Alabama has similar provisions in its laws and requires that all waste discharges be performed with the National Pollutant Discharge Elimination System permit from the state. In addition to fining non-complying biodiesel plants, Alabama orders them to undergo a Best Management Practices Review, and issue to the state a report ensuring future compliance. Many states and the federal EPA have declared that willful dumping/disposal of glycerin to surface water is a criminal violation of the Clean Water Act and may subject the violator to fines and criminal en- 
forcement [26-28].

\section{Concluding Remarks}

In various areas around the world, including arid regions of the Western and Southwestern U.S., dust poses serious and costly air quality problems, including visibility impairment in pristine areas, and local dust nuisance issues. To solve these problems, glycerin is proposed as a potential dust suppressant. There are a number of reports and patents indicating that glycerin can be effective in dust control applications, although detailed protocols of its application and use are generally lacking. Also, standard performance metrics are not available for assessing the effectiveness of glycerin's dust suppressant behavior.

Steady growth of the U.S. biodiesel industry continues to increase the amount of crude glycerin in the marketplace. The resulting abundance and low price of crude glycerin makes it economically attractive to apply aqueous glycerin solutions in dust suppression. However, the potential environmental impacts cannot be ignored, since damage due to irresponsible discharge of crude glycerin into rivers and wetlands has been reported in several states. Hence, there is a need to thoroughly investigate glycerin and other impurities during application in dust control, and subsequent potential impacts to the environment. Once crude glycerin is verified as an economically and environmentally sound dust suppressant, this could lower the cost of dust control, while improving the overall economics of biodiesel production.

\section{Acknowledgements}

We gratefully acknowledge financial support from the US Department of Energy (DE-EE0000600). The authors also acknowledge meaningful conversations with Dr. Chris Fritsen of the Desert Research Institute (DRI).

\section{REFERENCES}

[1] J. P. Engelbrecht and E. Derbyshire, "Airborne Mineral dust,” Elements, Vol. 6, No. 4, 2010, pp. 241-246. doi:10.2113/gselements.6.4.241

[2] J. M. Prospero, "Long-Range Transport of Mineral Dust in the Global Atmosphere: Impact of African Dust on the Environment of the Southeastern United States," Proceeding of the National Academy of Science, Vol. 96, No. 7, 1999, pp. 3396-3403. doi:10.1073/pnas.96.7.3396

[3] P. Ginoux, D. Garbuzov and N. C. Hsu, "Identification of Anthropogenic and Natural Dust Sources Suing Moderate Resolution Imaging Spectroradiometer Deep Blue Level 2 data,” Journal of Geophysical Research, Vol. 115, 2010, p. D05204. doi:10.1029/2009JD012398

[4] D. W. Griffin, “Atmospheric Movement of Microorganism in Clouds of Desert Dust and Implication for Human Health,” Clinical Microbiology Reviews, Vol. 20, No. 3,
2007, pp. 459-477. doi:10.1128/CMR.00039-06

[5] B. L. Tran and S. Bhattacharja, "Method for Preventing the Agglomeration or Generation of Dust from a Particulate Material Comprising Coal,” US Patent, 7,108,800 B2, 2006.

[6] B. L. Tran and S. Bhattacharja, "Method for Preventing the Agglomeration or Generation of Dust from a Particulate Material Comprising Coal,” US Patent Application Publication, No. 2006/0284137 A1, 2006.

[7] K. D. Burnside and J. C. Cranfill, "Dust Control Compositions and Method of Inhibiting Dust," US Patent Application Publication, No. 2009/0061102 A1, 2009.

[8] J. W. Smith and M. D. Key, "Hydrotropic Additives to Water for Dust Control,” US Patent, 7438286, 2009.

[9] J. C. Cranfill and K. D. Burnside, "Dust Control Compositions Having Reduced Corrosion and Method of Inhibiting Dust and Corrosion,” US Patent Application Publication, No. 2009/0061101 A1, 2009.

[10] B. R. Bhattacharyya and W. J. Roe, “Dust Control,” US Patent, 4417992, 1983.

[11] C. Rath and A. P. Verrall, "Method of Dust Abatement," US Patent Application Publication, No. 2008/055290 A1, 2008.

[12] J. A. Gillies, J. G. Watson, C. F. Rogers, D. Dubois, J. C. Chow, R. Langston and J. Sweet, "Long-Term Efficiencies of Dust Suppressants to Reduce PM10 Emissions from Unpaved Roads,” Journal of the Air \& Waste Management Association, Vol. 49, 1999, pp. 3-16.

[13] S. K. Hoekman, A. W. Gertler, A. Broch, C. Robbins and M Natarajan, "Biodistillate Transportation Fuels 1. Production and Properties," SAE Technical Paper Series No. 2009-01-2766, 2009.

[14] M. Gonzalez-Pajuelo, I. Meynial-Salles, F. Mendes, J. C. Andrade, I. Vasconcelos and P. Soucaille, "Metabolic Engineering of Clostridium Acetobutylicum for the Industrial Production of 1,3-Propanediol from Glycerol," Metabolic Engineering, Vol. 7, No. 5-6, 2005, pp. 329336. doi:10.1016/j.ymben.2005.06.001

[15] Y. Mu, H. Teng, D. J. Zhang, W. Wang and Z. L. Xiu, "Microbial Production of 1,3-Propanediol by Klebsiella Pneumoniae Using Crude Glycerol from Biodiesel Preparations,” Biotechnology Letters, Vol. 28, No. 21, 2006, pp. 1755-1759. doi:10.1007/s10529-006-9154-Z

[16] J. C. Thompson and B. B. He, "Characterization of Crude Glycerol from Biodiesel Production from Multiple Feedstocks," Applied Engineering in Agriculture, Vol. 22, No. 2, 2006, pp. 261-265.

[17] J. A. Kinast, "Production of Biodiesels from Multiple Feedstocks and Properties of Biodiesels and Biodiesel/ Diesel Blends,” NREL/SR-510-31460, 2003.

[18] R. Grogan, "Mixtures, Compositions and Methods of Suing and Preparing Same,” US Patent Application Publication, No. 2009/0269499 A1, 2009.

[19] J. R. Talamoni, “Dust Suppressant Composition,” US Patent, 7658862 B2, 2010.

[20] B. A. Grisso, R. E. Quinn and R. E. Kalhan, "Method of Using an Aqueous Composition Containing a Water-So- 
luble or Water-Dispersible Synthetic Polymer and Resultant Compositions Formed Thereof,” US Patent, 6372842, 2002.

[21] D. C. Roe and Z. C. Polizzotti, "Methods for Suppressing Fugitive Dust Emissions,” US Patent, 5194174, 1993.

[22] K. J. Zinkan and L. J. Koening, "Composition and Method for Dust Control,” US Patent, 4801635, 1989.

[23] M. Ogzewalla, "Dust Control of Solid Granular Materials,” US Patent Publication, No. 2009/0178452 A1, 2009.

[24] J. Taylor, "INSIGHT: US Glycerine Market Perspectives Fogged on Biodiesel Crude,” Chemical Industrial News \& Intelligence, 1 June 2011.

[25] National Biodiesel Board (NBB). http://www.biodiesel.org/. Last accessed 10/24/2011.

[26] "Environmental Laws Applicable to Construction and Operation of Biodiesel Production Facilities,” EPA-901B-08- 001, 2008 http://www.epa.gov/region7/priorities/agriculture/pdf/bio diesel_manual.pdf

[27] S. Smith, "Pollution Violations May Test Public Support for Biodiesel,” 2008. http://www.biodieselmagazine.com/articles/2383/pollutio n-violations-may-test-public-support-for-biodiesel

[28] Material Safety Data Sheet (Glycerin). http://www.sciencelab.com/msds.php?msdsId=9927350 